\title{
Publicação de Artista e Performance: Instersecções Entre Visibilidade e Valor da Aparência $^{1}$
}

Artist's Publications and Performance: Instersections Between Visibility And Face Value

Jenny Granado Rocha Borba ${ }^{2}$, Regina Melim³ 


\section{Resumo}

O presente artigo traz algumas articulações observadas na relação entre publicação de artista e performance. As investigações sobre o tema foram concentradas na trajetória da artista norte americana Martha Wilson, fundadora da Franklin Furnace, Inc., em Nova lorque, no ano de 1976. Como uma extensão de sua prática artística, a Franklin Furnace Inc. foi um espaço que, durante duas décadas, somou as atividades de construção de um arquivo de publicações de artista à um programa de performances. Como Martha Wilson, muitos artistas que faziam publicações impressas eram os mesmos que faziam performances - e que, na época, eram chamadas Leituras (Lectures). Por meio da interseção entre publicação e performance, a noção de alternative space expandiu-se de modo que poderíamos utilizá-la para desde exposições em páginas de revistas à manifestações de rua. A relação entre publicação e performance é tema a ser discutido no que nos tange o olhar de como tal interseção pode ser também uma resposta alternativa aos modos de criação/difusão de um trabalho de arte.

Palavras-Chave: Publicação de Artista, Performance, Espaços Alternativos.

\section{Abstract}

The present article brings some articulations toward the relationship between artistic publication and performance. The invertigations on the subject were focused on the trajetory of the north american artist Martha Wilson, founder of the Franklin Furnace Inc., in New York, in the year of 1976. As an extension of her artistic practice, Franklin Furnace Inc., was a room that for two decades summarized the activities of building an artistic publicational archieve with a performance program. Like Martha Wilson, many of the artists that made printed publications were the same as the ones who were performancers - and that at the time were called "Lectures". Through the intersection between publishing and performance, the sense of alernative space expanded so that we could use it for expositions in magazines as for street demonstrations. The relationship between performance and publication is a subject to be discussed on the look of how this so called intersection can be as well an alternate answer on the ways of creation/dissemination of an artistic work.

Keywords: Artist's Publications, Performance, Alternative Spaces.

ISSN: $1808-3129$

\footnotetext{
1 Vinculado ao Projeto de Pesquisa Exposições Impressas - 2562/2013 CEART - UDESC

2 Acadêmica do curso de Bacharelado em Artes Visuais CEART - UDESC bolsista PROBIC/UDESC
}

3 Orientadora, Prof. Dra. do Programa de Pós-Graduação em Artes Visuais da Universidade do Estado de Santa Catarina - UDESC, SC, Brasil 


\section{Martha Wilson}

"Livros de artista abrem caminho para mulheres artistas circularem seus trabalhos sem dependerem do sistema de museus e galerias, do qual não se pode depender (especialmente por não ser confiável para mulheres). Também servem como um veículo de baixo custo para ideias feministas. O próximo passo é colocar os livros em supermercados, onde serão folheados por mulheres que não iriam à Printed Matter ou leriam Heresies ${ }^{3}$, e normalmente dependeriam da Hallmark ${ }^{4}$ para comprar presentes. Eu tenho essa visão de livros de artistas feministas em bibliotecas escolares (ou sendo passados por baixo das carteiras), em salões de beleza, em salas de espera de ginecologistas, em biscoitos de escoteiras."

Lucy Lippard 5

"O artista opera a partir do vácuo deixado quando todos os outros valores são rejeitados."

Martha Wilson ${ }^{6}$

A intersecção existente entre publicações de artista e performance, tema que o presente artigo tratará, foi o impulso chave que nos levou à trajetória da artista Martha Wilson e da sua fundação sem fins lucrativos, a Franklin Furnace, Inc - um espaço em Nova lorque no qual essas duas manifestações, performance e publicação, contaminaram-se de maneira profunda por meio de exposições e da construção de um arquivo, seguido de um programa de apresentações de performances.

Nascida na Pensilvânia, Filadélfia, Martha Wilson mudou-se para Halifax, no Canadá, permanecendo entre os anos de 1969 a 1974, segundo ela mesma, por razões pragmáticas e políticas, como: melhores bolsas e em forma de protesto à investida de Richard Nixon na Guerra do Vietnã. Nesse período foi estudante de Literatura Inglesa na Universidade de Dalhousie e, após um ano de pesquisa teve sua tese de doutorado rejeitada por sua supervisora sob a alegação de que seu trabalho pertencia mais às "artes visuais" do que à "literatura"7. Após esse episódio, passa a lecionar inglês na Scotia College of Art and Design, ambiente de forte fluxo da comunidade de artistas da arte conceitual, onde, mais tarde, em 1973, conhece Lucy Lippard.

$\mathrm{Na}$ transição entre as duas instituições, Martha Wilson não abandona a literatura. Pelo contrário, seu desligamento da Dalhousie só reforça seu interesse nas artes e no cruzamento das duas áreas. Em 1971 ela dá início a uma produção em formato de foto-texto e vídeo na qual levanta questões sobre a visibilidade e o valor da aparência. Esses trabalhos também antecipam alguns importantes conceitos das investi-

\footnotetext{
3 Heresies: A Feminist Publication on Art and Politics, foi um jornal publicado entre 1977-1992 em Nova lorque pelo Heresies Collective

4 Hallmark Licensing, Inc foi uma empresa americana fundada em 1910 por Joyce C. Hall que começou vendendo cartões postais para o Dia dos Namorados e Natal. Em 2001, a Hallmark inaugurou o seu próprio canal de televisão por assinatura, o Hallmark Channel

5 In: WILSON, Martha. Martha Wilson Sourcebook: 40 years of Reconsidering Performance, Feminism, Alternative Spaces. NY: Independent Curators International, 2011. Tradução da autora.

6 A portfolio of Models, Martha Wilson, 1974

7 Wark, Jayne. "Martha Wilson: Not Taking It at Face Value". In: Martha Wilson: photo/text works, 1971-74, catálogo de exposição. Nova lorque: Mitchell Algus Gallery, 2008.
} 
gações do feminismo, que anos mais tarde, teóricas como Judith Butler formulariam como performatividade de gênero ${ }^{8}$.

O afastamento do doutorado foi um marco importante para a produção de Wilson. Ele definiu suas estratégias artísticas e políticas, pautando sua opção por resistir à lógica institucionalizante - também patriarcal e hierárquica - da arte. Assim como outros grupos de artistas, principalmente a partir do final dos anos 1960, Martha Wilson, em resposta ao mercado, criou espaços alternativos (não apenas tridimensionais; teto, chão, parede) para a criação/difusão de trabalhos de arte. Tais espaços alternativos eram extremamente variáveis na sua concepção, podendo ser desde a realização de manifestações na rua, como ações em rádio, páginas de catálogos, revistas ou jornais, vídeos, entre outros. Entre 1978 e 1982, Wilson integrou a Disband, uma banda experimental formada apenas por mulheres, que, mesmo não sabendo tocar quaisquer instrumentos, faziam uso principalmente da palavra e do ruído para transmitir suas mensagens.
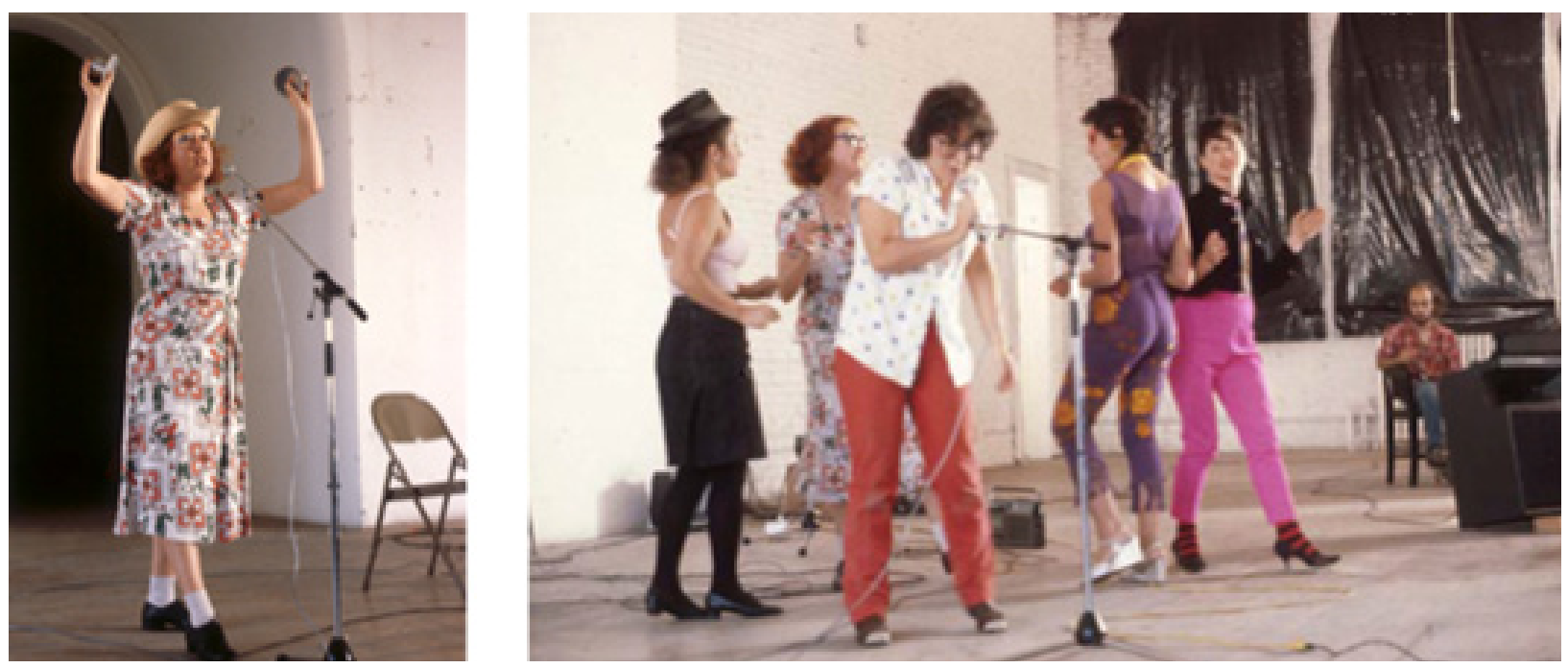

Disband em apresentação no MoMA PS1, Nova lorque, 1979.

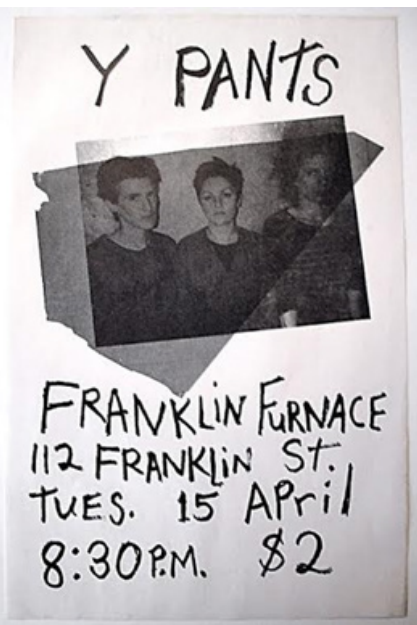

Cartaz-Convite para apresentação da Disband na Franklin Furnace, Inc.

8 Cf. Wark, Jayne. Martha Wilson, op. cit. Para a formulação de Butler, ver Butler, Judith P., Problemas de gênero: feminismo e subversão da identidade. Rio de Janeiro: Civilização Brasileira, 2003. 
Com a Franklin Furnace, Inc., inaugurada por ela em Nova lorque no ano de 1976, recebeu outros tantos artistas e a comunidade do entorno do bairro Tribeca, na zona industrial de Manhattan. Os projetos ali realizados, que envolviam investigações e experimentações através da linguagem de vanguarda e do corpo, propunham o embate com certas formas e estruturas artísticas, políticas e de gênero, engessadas por uma sociedade patriarcal e pela tradição artística que as marginalizava.

Assim, Martha Wilson, avessa ao empoderamento que a classe artística (predominantemente masculina) mantinha, através de um processo de desconstrução ${ }^{9}$ de qualquer identidade que pudesse vir a privilegiá-la, buscava afirmar sua independência tanto como mulher quanto como artista, imbricando tais papéis numa postura não conformista. Tal postura aparece, tanto no seu trabalho pessoal, explicitamente íntimo, sincero e feminista, quanto nas suas ações dentro da Franklin Furnace, Inc. - espaço onde as análises críticas de Martha Wilson evoluíram e tomaram corpo na forma de publicações e performances. A "desconstrução" operada por suas ações, pessoais ou públicas, refletem uma preocupação ativa, portanto, política e moral, oposta à construção de um papel social pautado pela mera aparência e baseado num sistema pré-julgado de valores, sejam lá quais fossem.

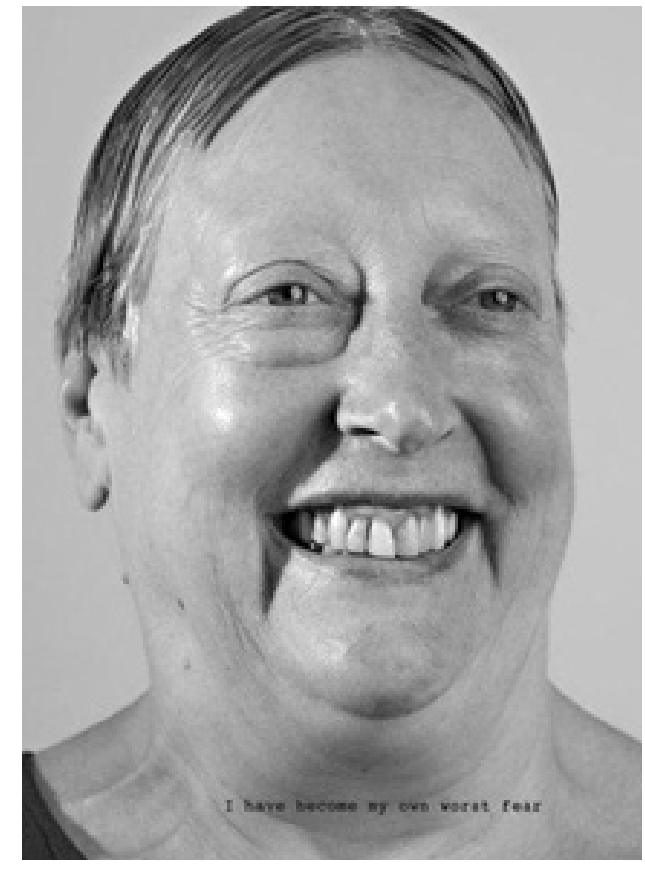

Martha Wilson, "I have become my own worst fear". P.P.O.W Gallery, Nova lorque, 2011.

2. Franklin Furnace, Inc.

Em 1974, Martha Wilson muda-se de volta para os Estados Unidos estabelecendo-se em Nova lorque. Inicialmente, a organização que veio a ser chamada de

9 "A origem do termo 'desconstrução' vem de Heidegger, que propôs, no período inicial de sua trajetória, um projeto filosófico chamado destruição da metafísica, o qual, por sua vez, procurava libertar os conceitos herdados da tradição que haviam se enrijecido - há muito sedimentadas pelo hábito de sua transmissão -, e retorná-los à experiência de pensamento original. Tratava-se, portanto, de um projeto em nada destrutivo, no sentido de um simples aniquilamento, e que Heidegger pôde nomear com a palavra alemã Destruktion. Ao passar para o francês, Derrida percebeu ser impossível evitar esta conotação fortemente negativa da palavra 'destruição'; o termo 'desconstrução' lhe pareceu então mais apropriado para captar essa ideia inicial contida no projeto de Heidegger, o que não quer dizer que a desconstrução seja uma simples repetição do projeto heideggeriano". (Paulo Cesar DUQUE-ESTRADA, 2005). 
Franklin Furnace, Inc. fazia parte de um projeto maior, o da Franklin Street Arts Center - ideia encabeçada por Willoughby Sharp, fundador da revista Avalanche ${ }^{10}$. Sharp arrendou um edifício no Tribeca junto com outros seis artistas, que deveriam dividir-se para ocupar cada um dos cinco andares, com diferentes propostas, tais como, livraria, teatro, sala para vídeos, entre outras atividades ${ }^{11}$.

O desejo em comum para o espaço era abrigar produções artísticas e exibi-las em eventos públicos - o que era, além de tudo, propício para que a comunidade e a vizinhança pudessem se reunir. No entanto, apenas Sharp e Wilson mantiveram suas intenções iniciais de atuação nos andares que ocuparam. Ele fazendo vídeos e mantendo uma sala para exibição dos mesmos, e ela somando esforços para montar seu arquivo de publicações de artista. Havia no piso térreo algumas estantes, e isso foi o suficiente para que Martha Wilson elegesse, na divisão dos lofts, aquele espaço como seu.

Sua motivação maior para a criação de um espaço dedicado à publicações de artista advinha do fato em perceber o quanto as instituições de arte, como museus e galerias, deixavam de lado ou simplesmente não consideravam "arte" os trabalhos de natureza efêmera (publicações de artistas, performances e/ou instalações). Tais manifestações pouco ou quase nada atraiam essas instituições. Wilson vinha produzindo livros de artista, assim como seus colegas da arte conceitual e sua intenção ao criar a Franklin Furnace, Inc. era montar um acervo-biblioteca com o material que já possuía e o que viria a reunir no decorrer dos anos.

Foi Willoughby Sharp quem concebeu o nome "Franklin Furnace". À princípio, Martha Wilson pensava em chamar de "Franklin Stove". Mas a sugestão de Sharp vingou e, desde então, "Franklin Furnace" passou a não se referir unicamente à mina de carvão localizada no estado de Nova Jersey, conhecida pela extração de minerais raros, mas também como um forno aquecido no número 112 da Franklin Street. Como um ambiente que estimularia a efervescência experimental na cidade de Nova lorque, por meio de programas educacionais e culturais, fomentando a produção de formas ignoradas e marginalizadas de se fazer arte.

Depois de se instalar no início de 1976, na Franklin Street, Martha Wilson passou três meses recolhendo livros e enviando cartas com pedidos para que os amigos lhe enviassem material impresso. Nem mesmo os próprios artistas sabiam o que fazer com muitos desses materiais que, por causa do pedido de Wilson, acabaram chegando na Franklin Furnace. No dia 3 de abril de 1976, Martha Wilson inaugurou, com cerca de 200 exemplares, o espaço que viria a abrigar o maior acervo de publicações de artistas dos Estados Unidos.

10 Em 1968 a revista Avalanche (em circulação de 1970-76) foi fundada por Willoughby Sharp em conjunto com a escritora e filmmaker Liza Bear, que publicavam entrevistas conduzidas por eles com artistas contemporâneas tais como Vito Acconci, Dennis Oppenheim e Yvonne Rainer. Avalanche ficou reconhecida como um importante canal para divulgação de performances realizadas na primeira metade da década de 1970, em Nova lorque.

11 Os artistas eram: Willoughby Sharp Duff Schweniger, Virginia Piersol, Patrick McEntee, Kurt Maneske, Martha Wilson, Haviland Wright. Eles tinham um acordo entre as partes de que Haviland e Martha Wilson dividiriam o térreo, Willoughby instalaria-se no andar superior, Virginia no terceiro andar, e assim por diante. 


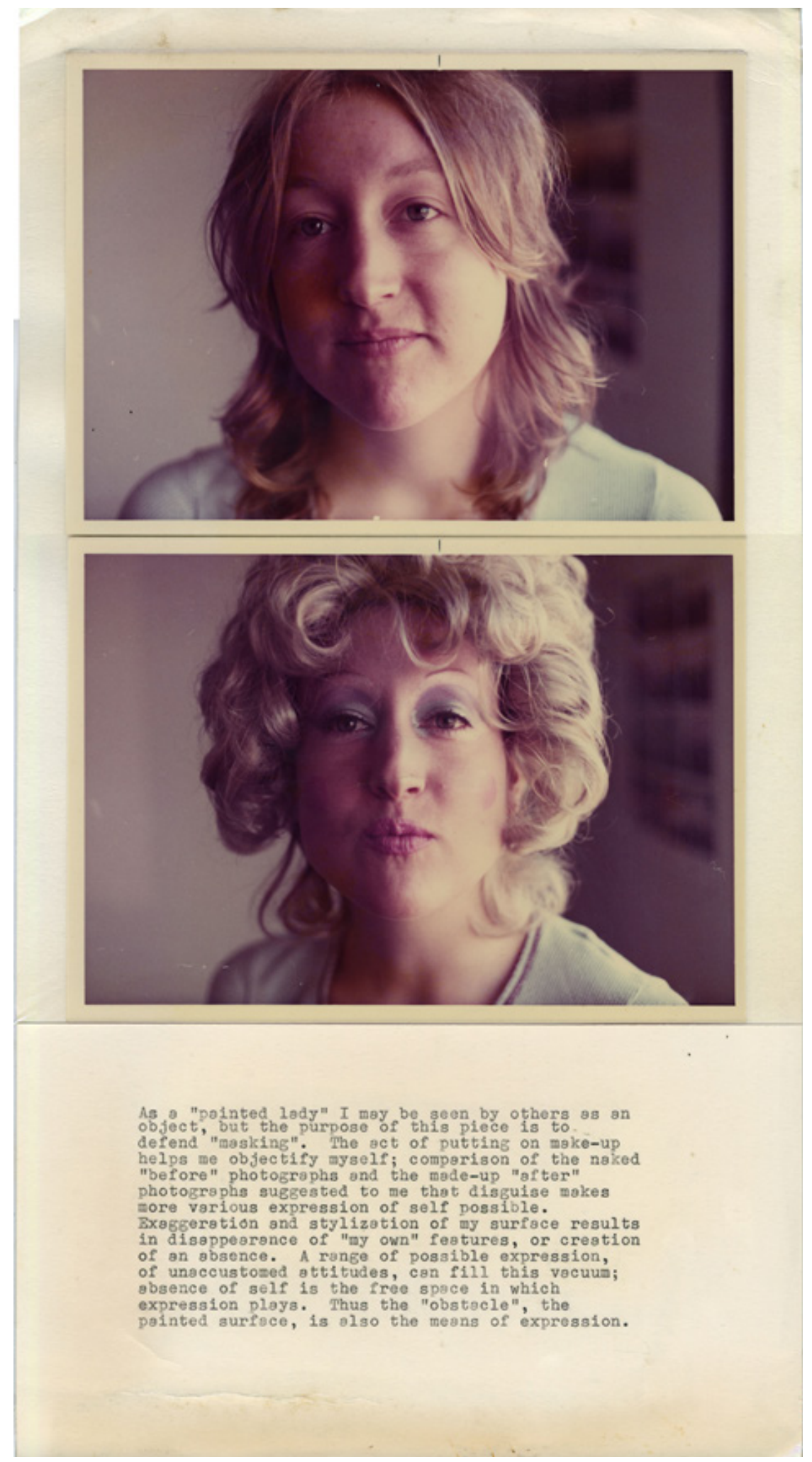

Martha Wilson, "Painted Lady", 1974 


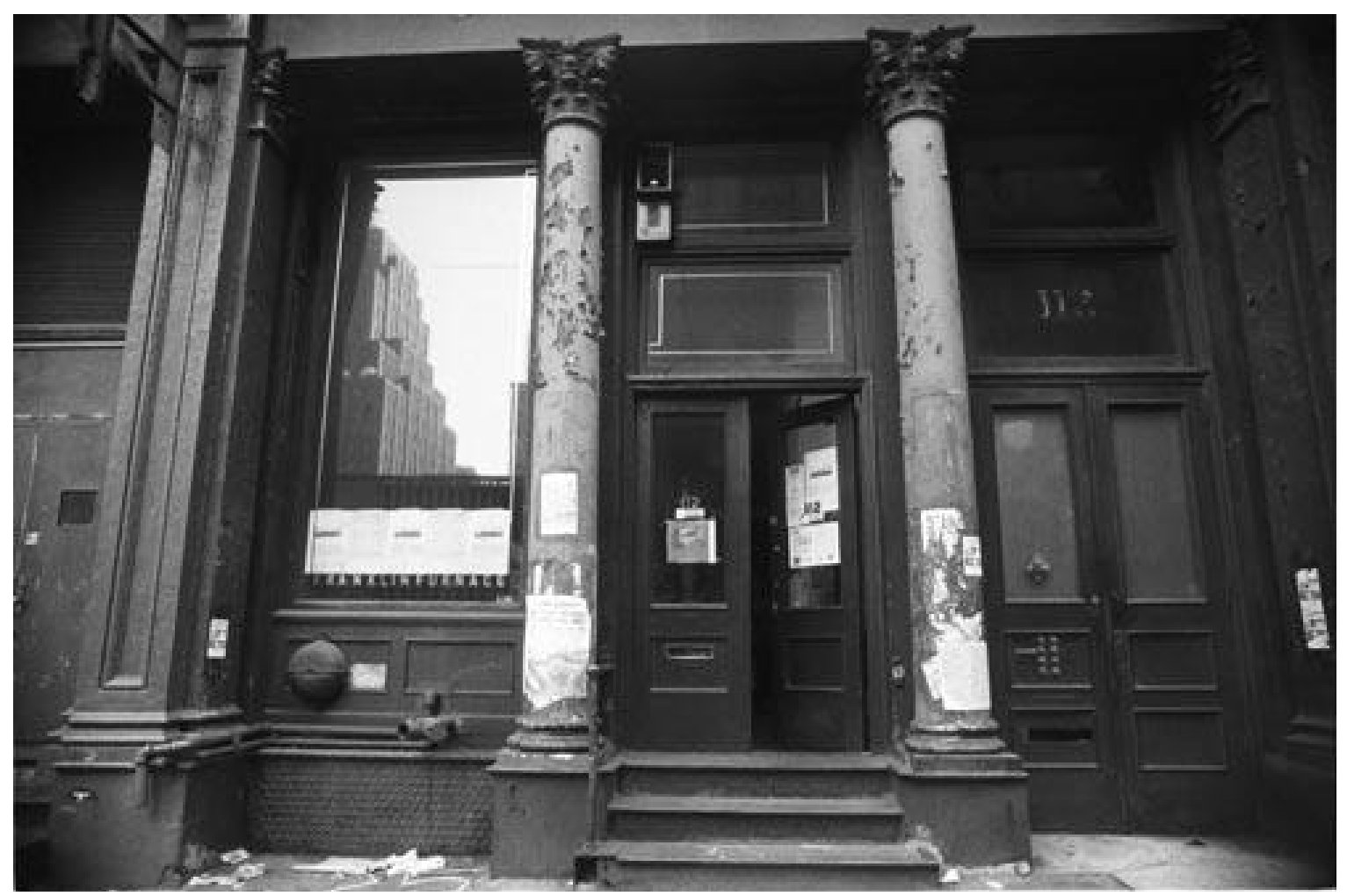

Fachada da Franklin Furnace Inc., Tribeca, Nova lorque, 1978

Alguns meses depois, em julho de 1976, nesse mesmo local, foi criada uma livraria por um grupo de doze pessoas, com interesses muito próximos aos de Martha Wilson. Tratava-se da Printed Matter e entre essas doze pessoas estavam Sol LeWitt e Lucy Lippard. Além de livraria, a Printed Matter tinha também o objetivo de publicar livros que as editoras comerciais não estavam interessadas e os artistas não podiam pagar. A distribuição também era algo que estava na pauta de suas discussões pois, no processo de publicar livros, a distribuição demandava a mesma importância que a edição e a produção ${ }^{12}$.

A parceria entre as duas organizações foi bem forte no início de suas atividades. Na divisão de tarefas, a Franklin Furnace era responsável por catalogar, apresentar e preservar os trabalhos, enquanto a Printed Matter publicava e vendia arte impressa. As duas organizações operavam juntas, em contrapartida à negligência de outras instituições, que achavam o conteúdo de tais arquivos desinteressantes e politicamente impopulares. Além de manter a coleção, a Franklin Furnace encorajava outras atividades relacionadas ao arquivo de publicações de artista, como as Leituras feita pelo próprios artistas, atividade que logo evoluiu para o programa performance.

\section{Do arquivo às performances}

Identificando a importância da confecção dos livros pelos próprios artistas, a

12 MELIM, Regina et all. ¿Hay en Portugués?, número três, maio/junho, 2014. 
Franklin Furnace buscava dar visibilidade a esse tipo de produção. Os livros eram tratados como uma mídia que não apenas falava sobre arte, mas era a arte em si ${ }^{13}$ , o que colaborou no sentido de atribuir importância artística fundamental a esse campo de atuação. Desde o início da criação da Franklin Furnace, Martha Wilson cuidava para que esse formato fosse (e se mantivesse) acessível ao público. A criação de espaços alternativos - não necessariamente tridimensionais, com endereços fixos onde a correspondência pudesse chegar de forma segura - era uma saída para a desinstitucionalização da arte. Um de seus principais objetivos era a diluição da ideia de "centros" específicos de legitimação. A ocupação em páginas de catálogos, jornais, revistas, enfim, diferentes meios impressos, tornava-se uma opção cada mais vez mais utilizada para a disseminação de ideias e a desmistificação de tais centros. Tais mídias permitiriam que os trabalhos circulassem fora do esquema tradicional de exposição, e atingissem o público sem a necessidade do "consentimento" institucional/comercial desses espaços: "Os livros de artistas oferecem uma crítica alternativa a esses sistemas, contornando-os"14.

Não por coincidência, como nota a própria Martha Wilson, aqueles mesmos artistas marginalizados, que trabalhavam com performances, experimentações sonoras e instalações, eram os mesmos que faziam livros de artistas. Os próprios artistas estavam interessados em experimentar os diferentes processos de criação ao invés de separá-los por categorias. Por isso mesmo, a dificuldade no processo de assimilação (que ainda perdura) pelos museus, e sua insistência na catalogação compulsória desse material - o que condiz e alimenta a valorização financeira do trabalho de arte que circula a partir da lógica de mercado ${ }^{15}$.

Como muitos dos artistas que produziam arte impressa eram os mesmos que faziam performances e/ou instalações, o entrosamento entre o arquivo e as exposições, por mais que parecesse natural, não aconteceu de imediato. Três meses se passaram até que a primeira Leitura acontecesse, em junho de 1976 .

Jackie Apple, artista norteamericana com quem Martha Wilson trabalhou por muitos anos, tornou-se curadora das Leituras assim como das window works, programa temporário de instalações para a fachada da Franklin Furnace. Assim como Lucy Lippard, Apple teve grande importância na formação profissional e pessoal de Martha Wilson. Ela e Wilson começaram a corresponder-se a partir da exposição c. 7,500, realizada em 1973, organizada por Lippard e que contava apenas com artistas mulheres.

13 Definição sobre "publicações de artista" de Willoughby Sharp apud LIPPARD, Lucy. Six years: the dematerialization of the art object from 1966 to 1972 . Berkeley: University of California Press, 1997, op. cit.

14 Em "O que são livros de artistas?" https://printedmatter.org/what_we_do/what_is_an_artists_book

15 Em referência a divisão feita pelo MoMA do acervo Fluxus em tres partes: publicações, documentação e "trabalhos de arte". 0 comentário da arquivista responsável pela coleção no site do MoMA, Julia Pelta Feldman, reforça a lógica mercadológica da legitimação do trabalho de arte comentada acima: "The decisions made by myself and the other members of the Fluxus team affect what goes into the galleries, and how those objects are presented to the public". Mais informações em: http://www.moma.org/explore/inside_out/2013/05/30/gilbert-and-lila-silverman-fluxus-collection-archives-open-for-research . ¿Hay en Portugués?, número três, maio/junho, 2014. Martha Wilson quando vendeu sua coleção deixou claro ao museu que a mantivesse inseparável. 


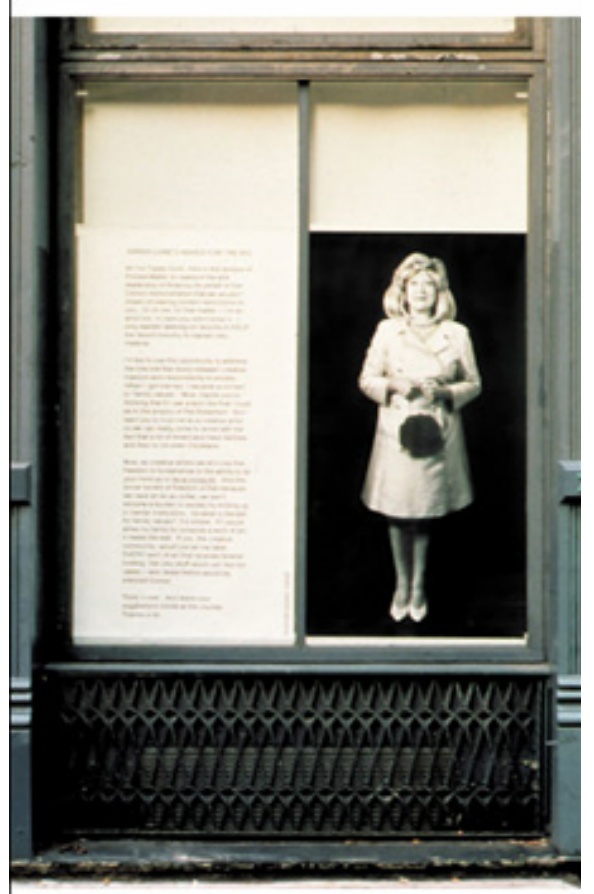

Martha Willoon as Tipper Gore "Tipper Gore's Advice for the 900," 1994 misdow installasion commissicend by Primted Matter, Inc. artists book

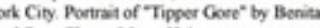

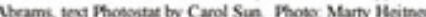

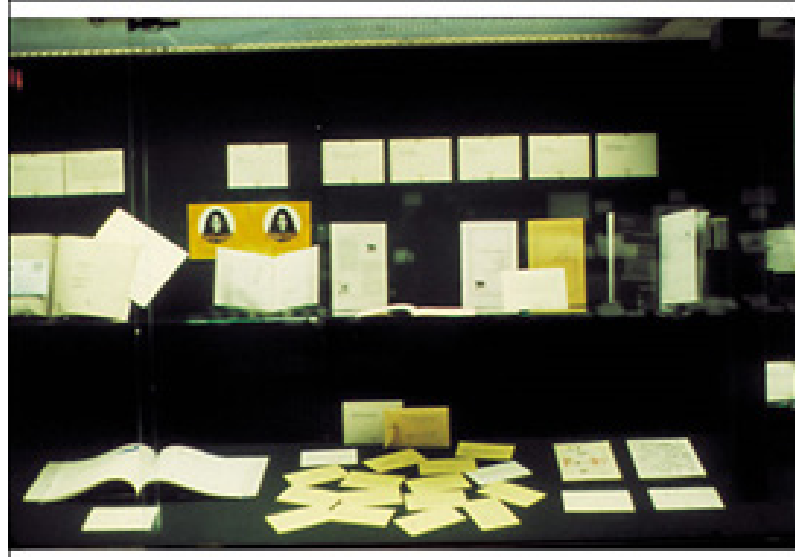

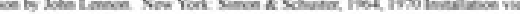

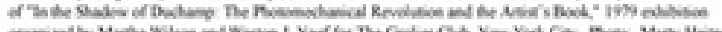

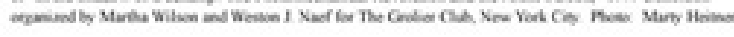

"Window Works"

Artistas como Jenny Holzer e Barbara Kruger estavam interessadas no texto como arte visual, e acabaram por estar muito presentes na história da Franklin Furnace, porém foi Martine Aballea que, por convite de Jackie Apple, iniciou o programa de Leituras. A ideia era que os mesmos artistas que estavam publicando livros pudessem ser convidados para ler seu material impresso, e que estava na coleção da Franklin Furnace.

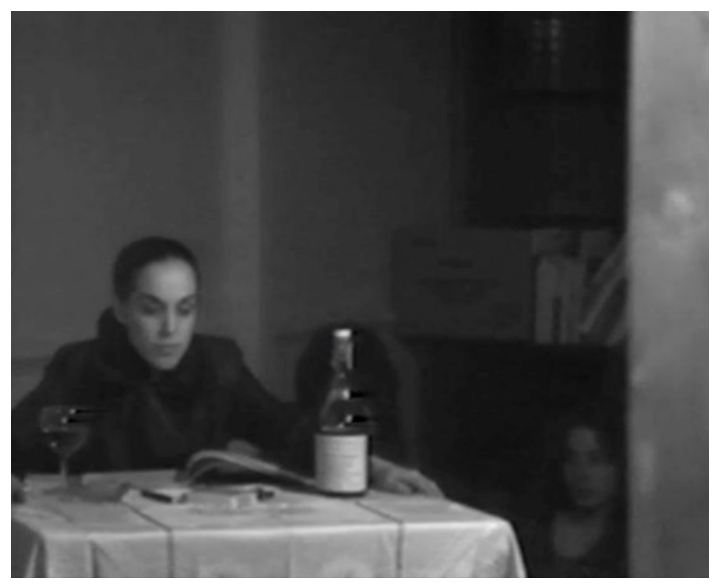

Martine Aballea, junho de 1976 na primeira Leitura da Franklin Furnace

16 É importante salientar que durante toda a década de 1970 apenas o jornal Village Voice trazia informações e discussões acerca de experimentos híbridos que agrupavam performances, publicações de artistas e instalações. Uma razão para isso, talvez, possa ser esclarecida por conta de que entre os integrantes da equipe de jornalistas do Village Voice encontrava-se uma delas que era muito próxima de Martha Wilson. O jornal New York Times, por outro lado, manteve até os anos 1980 todas as informações e divulgações sobre tais acontecimentos híbridos dentro da categoria Teatro.

17 c. 7,500 - fez parte da última série das Exposições Números organizada por Lucy Lippard, durante os anos de 1968 a 1973 . O número indicava a população local, nesse caso, Valência, na Califórnia, local onde iniciou essa exposição que itinerou por sete diferentes cidades. 0 catálogo era composto de uma série de fichas soltas, que poderiam ser embaralhadas e lidas conforme a vontade de cada um. 
Desde o inicio da criação da Franklin Furnace, as denominações performances para publicação, performances registradas em publicações ou performances como instrução, eram tratadas indistintamente, aderidas e compostas unicamente como publicações-performances. Desse modo, a página impressa estava sendo considerada não apenas um espaço alternativo, mas era possível entender como as performances (Leituras) davam forma corporal àquelas ideias impressas, expandindo assim a própria noção de publicação. Segundo Martha Wilson: "Tanto o livro de artistas como a performance contêm potencial de comunicação incrivelmente poderoso"18 . E ainda acrescentava: "O denominador comum entre livros de artista, performance e instalações é a noção de broadcast (difusão, transmissão)"19.

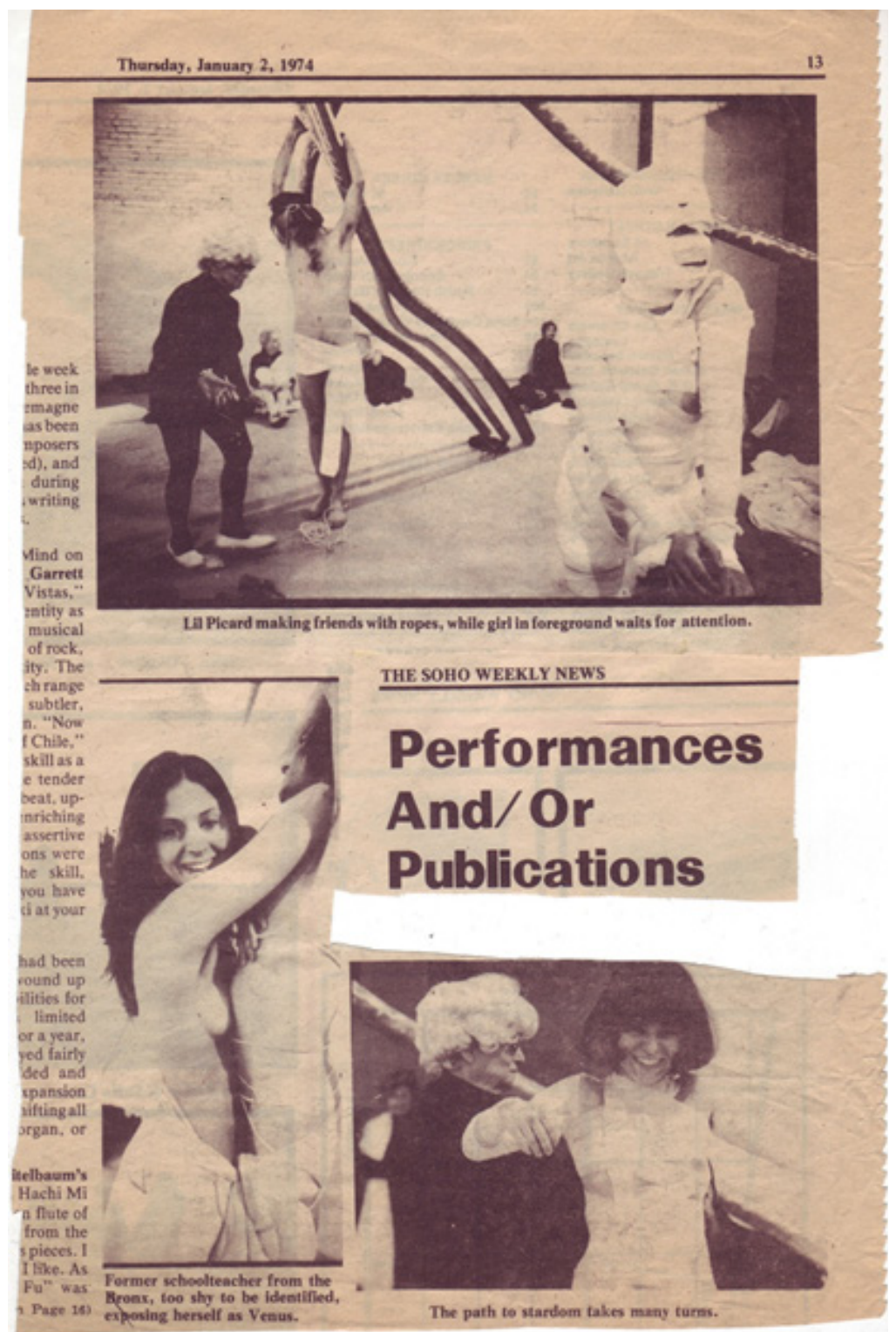

Jornal The Voice Village

18 Conversa entre Martha Wilson e Britta Wheeler. http://bombmagazine.org/article/6158/martha-wilson 19 Martha Wilson em entrevista via skype com Michele Schiocchet, Nova lorque, 2 de março de 2014, publicada na ¿Hay en Portugués? número três. maio/ junho de 2014. 
A intersecção entre publicação e performance ocorreu pela primeira vez de maneira geográfica, no próprio espaço da Franklin Furnace. Era preciso atravessar o arquivo para poder chegar ao espaço das apresentações, que aconteciam no porão. Além disso, não havia uma clara distinção de qual trabalho os artistas estavam executando no momento, as mídias se mesclavam e as instalações seguiam conjuntas ao arquivo e as performances. O que interessava é que quem passasse por ali teria a possibilidade de experimentar, simultaneamente, estudo e discussão, assim como novas formas de expressão por meio de uma arte que era, por natureza, efêmera. $\mathrm{Na}$ Franklin Furnace os artistas vivenciavam muito daquilo que Lucy Lippard descreve nas mais de trezentas páginas de seu livro "Six Years: the dematerialization of the art object from 1966 to 1972"20: uma arte que se desmaterializava-se e transitava entre muitos meios e suportes.

Nos primeiros trabalhos de foto-texto de Martha Wilson, sua formação em literatura e o pensamento imerso em arte visual elucidam e antecipam uma prática que a interessava desde cedo: a manifestação da arte em diversas formas e que escapassem dos sistemas reguladores de categorização. A criação da Franklin Furnace era, também, um espaço alternativo para dar estofo a si mesma, mantendo o desejo da expansão dos conceitos que envolvem as artes visuais.

O programa de performance da Franklin Furnace serviu justamente para unir interesses, tornando-se parte de um projeto emancipatório.

Contraditoriamente, tais experiências também levaram à formação de um novo regime de legitimação para os artistas considerados anteriormente "marginais". Entre esses artistas, que tornaram-se internacionalmente reconhecidos após suas apresentações na Franklin Furnace, estão: Annie Sprinkle, Karen Finley, David Cale, Ana Mendieta, Vito Acconci, Coco Fusco, Frank Moore, Patty Chang, Willie Cole, Nicole Eisenmann, Guillermo Gómez-Pena, Robbie McCauley, Laurie Anderson, Cheri Gaulke e Johanna Went ${ }^{21}$.

\section{4 . Das performances "em exílio" aos dias atuais}

Vários artistas, como Sprinkle, Cheri Gaulke, Frank Moore, Johana Went e Karen Finley, que fizeram parte do programa de performances e instalações da Franklin Furnace, trabalhavam quase que estritamente com conteúdos explicitamente sexuais. Motivos esse que, de maneira velada, viriam a influenciar o posterior fechamento do espaço.

Em 1990, a instalação A Woman's Life Isn't Worth Much, de Karen Finley e sua performance "Voyers's Delight", geraram rebuliço na comunidade ativista cristã local,

\footnotetext{
20 Título original "Six Years: the dematerialization of the art object from 1966 to 1972: a cross-reference book of information on some esthetic boundaries: consisting of a bibliography into which are inserted a fragmented text, art works, documents, interviews, and symposia, arranged chronologically and focused ons o-called conceptual or information or idea art with mentions of such vaguely designated áreas as minimal, antiform, systems, Earth, or process art, occurring now in the Americas, Europe, England, Australia, and Asia (with occasional political overtones), edited and annotated by Lucy R. Lippard." Berkeley: University of California Press, 1997. Lucy Lippard reforçava o pedido para que nas reproduções e edições de seu livro o título fosse mantido dessa forma.

21 Annie Sprinkle, por exemplo, inicia uma entrevista dizendo que perder sua virgindade não foi tão importante quanto sua primeira performance (que aconteceu na Franklin Furnace à convite de Martha Wilson), e ressalta dizendo que o acontecimento mudou sua vida para sempre.
} 
o que levou a Franklin Furnace ao tribunal por três vezes, no verão daquele ano, para responder às acusações de organizações católicas e moralizadoras. As acusações diziam que a Franklin Furnace era um "clube", e que os trabalhos ali expostos não deveriam ser financiados com dinheiro público, o que reflete o caráter tradicionalista de uma sociedade que se apavora ao ver uma mulher reempoderando-se daquilo que lhe foi tomado por uma educação sob o jugo do falocentrismo: seu próprio corpo. Karen Finley teve seus trabalhos retirados do financiamento do NEA e Frank Moore chegou a responder na GAO23 por supostamente encenar "conteúdo obsceno".

A Franklin Furnace foi proibida de dar continuidade ao programa de performance numa alegação emitida pelo corpo de bombeiros (o New York City Fire Departament), que fechou o espaço alegando inadequação às normas de segurança. A partir de então, as performances "em exílio" (segundo a expressão de Martha Wilson) foram sendo apresentadas em espaços de outras pessoas, na rua e algum tempo depois, na internet. As instalações seguiram até 1997, quando a Franklin Furnace se mudou para a John Street, uma estreita rua vizinha as torres do World Trade Center.

A coleção de livros de artista da Franklin Furnace havia se tornado a maior dos Estados Unidos e, em 1993, foi adquirida pelo MoMA 24 (Museu de Arte Moderna de Nova lorque). A partir daí, a Franklin Furnace tomou outros rumos no seu papel de difusora da arte de vanguarda direcionando-se à absorção das novas tecnologias como plataforma. As performances, que já eram apresentadas em outros espaços desde 1990, foram migrando progressivamente para as mídias virtuais, passando da televisão para a internet. Assim, Martha Wilson continuou explorando o que chamamos aqui de espaço alternativo.

Em 1994, via webcam por controle remoto, Nina Sobell e Emily Hartzell executaram na Franklin Furnace a Park Bench's Artist Theater, a primeira performance na internet de que se tem registro ${ }^{25}$. Esse salto das apresentações do espaço físico para o virtual, e mesmo a digitalização da coleção, o que deu início a uma discussão sobre qual seria o espaço real e o virtual durante uma apresentação transmitida à distância.

Em 2001, impossibilitados de permanecer na John Street após o 11 de setembro, a Franklin Furnace foi uma das 13 organizações sem fins lucrativos a mudar o seu endereço para o Brooklyn, e hoje ocupa um espaço no edifício chamado 80 Arts, na Hanson Place, conhecido como BAM Cultural District. Nesse período estruturaram-se novos projetos educacionais ${ }^{26}$, ao mesmo tempo em que digitalizavam a coleção e migravam para as mídias virtuais: "À medida que a internet se tornava um local de mais valor para a difusão da arte, começamos a utilizar a internet também como meio de arte $27 "$. Martha Wilson olha para a internet como, nos anos 1970, olhava para o

22 https://www.neafoundation.org/

23 GAO: Government Accountability Office é o órgão responsável pela Auditoria, Avaliações e Investigações do Congresso dos Estados Unidos. fonte: http:// pt.wikipedia.org/wiki/Government_Accountability_Office

24 É importante assinalar que a coleção de livros de artista quando adquirida pelo MoMA levou junto consigo uma vontade expressa de que estes jamais poderiam ser separados e classificados em categorias distintas. A coleção é mantida até hoje como um conjunto e sob a denominação MoMA/FF/Artist Book Collection. Vide nota 16.

25 Mais informações em : http://franklinfurnace.org/research/essays/pdfs/leonardoMartha.pdf

26 A Franklim Furnace promoveu desde programas subversivos de alfabetização para crianças, o Sequential Art for Kids a demostrações de ejaculação feminina por estrelas do mundo pornô feminista. 0 propósito beneficente da Franklin Furnace não é a arte, mas sim a educação, e até hoje continua a trabalhar desta forma em seu atual endereço.

27 Em PADON, Thomas. Interview with Martha Wilson. In LAUF, Cornelia, PHILPOT, Clive. Artist/Autor - Contemporary Artist's Books. NY: Dristributed Art Publishers, 1998, pp. 108-124 
espaço de arquivo e apresentações de performances e instalações, como um lugar para experimentações, exposições e circulação de um trabalho artístico.

Os livros de artista, colecionados desde a fundação da Franklin Furnace estão no MoMA, preservados e conjugados sob o titulo 'Museu de Arte Moderna/Coleção de Livros de Artista Franklin Furnace'.

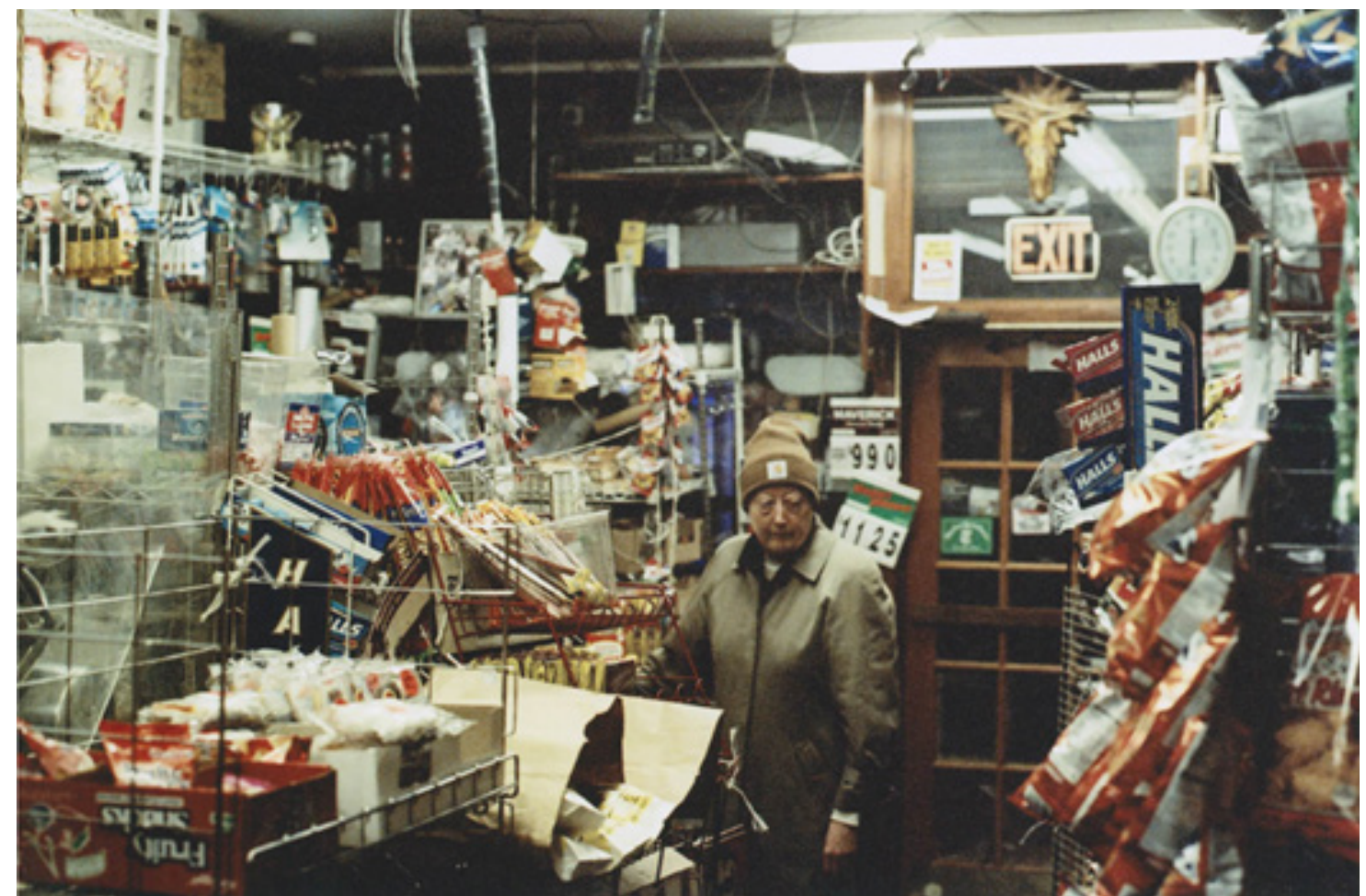

"Invisible" Martha Wilson, 2011

\section{Referências Bibliográficas}

LIPPARD, Lucy. Six years: the dematerialization of the art object from 1966 to 1972. Berkeley: University of California Press, 1997.

MELIM, Regina et all. ¿Hay en Portugués?, número três, maio/junho, 2014.

PADON, Thomas. Interview with Martha Wilson. In: LAUF, Cornelia, PHILPOT, Clive. Artist/Autor - Contemporary Artist's Books. NY: Dristributed Art Publishers, 1998, pp. 108-124

ROCHA, Michel Zózimo. Estratégias Expansivas: publicações de artistas e seus espaços moventes. Editora do Autor. Porto Alegre, 2011.

Wark, Jayne. Martha Wilson: Not Taking It at Face Value. In: Martha Wilson: photo/text works, 1971-74, catálogo de exposição. Nova lorque: Mitchell Algus Gallery, 2008.

WILSON, Martha. Martha Wilson Sourcebook: 40 years of Reconsidering Performance, Feminism, Alternative Spaces. NY: Independent Curators International, 2011.

WHEELER, Britta. Conversa entre Martha Wilson e Britta Wheeler. In: Bomb Artists in Conversation. http://bombmagazine.org/article/6158/martha-wilson 